\title{
Paraneoplastic Sensory Polyneuropathy Related to Anti-PD-L1-including Anticancer Treatment in a Patient with Lung Cancer
}

\author{
Toshiki Morimoto ${ }^{1,2}$, Takeshi Orihashi ${ }^{1}$, Kei Yamasaki $^{2}$, Masahiro Tahara ${ }^{2}$, \\ Kaori Kato ${ }^{2}$ and Kazuhiro Yatera ${ }^{2}$
}

\begin{abstract}
:
Paraneoplastic neurological syndromes (PNS), such as sensory polyneuropathy, are rare, and serum neuronal antibodies that are used for diagnosing this syndrome are occasionally positive. Similarly, neurological immune-related adverse events due to immune checkpoint inhibitors (ICIs) are also rare. However, their etiologies and the relationship between them remain unclear. We herein report a patient with suspected small cell lung cancer who showed sensory polyneuropathy after treatment with atezolizumab in combination with cytotoxic agents (carboplatin and etoposide) and was doubly positive for serum anti-Hu and anti-SOX-1 antibodies. Treatment with ICI and cytotoxic agents may sometimes lead to the development of PNS.
\end{abstract}

Key words: small cell lung cancer, paraneoplastic neurological syndrome, immune checkpoint inhibitors, anti-neuronal antibodies, anti-Hu antibody, sensory polyneuropathy

(Intern Med 60: 1577-1581, 2021)

(DOI: 10.2169/internalmedicine.5629-20)

\section{Introduction}

Paraneoplastic neurological syndromes (PNS) are defined as remote effects of cancer unrelated to direct effects of tumors or metastases and are exceedingly rare, affecting less than $1 / 10,000$ cancer patients (1). Neuronal anti-Hu and anti-SOX-1 antibodies are sometimes detected in patients with PNS in the serum or cerebrospinal fluid, and the clinical signs are different from the main symptoms of cancer.

In general, neurological symptoms tend to progress subacutely and cause severe physical dysfunction. In about $80 \%$ of patients, the onset of neurological symptoms and the detection of antibodies precedes the detection of cancer by months to years; therefore, early antibody detection may be useful for predicting PNS.

Immune checkpoint inhibitors (ICIs) have widely been used in the treatment of multiple types of cancer. The main side effects of ICIs are immunological; thyroid function disorders are common, and organ-related side effects are also prevalent (2). Among these side effects, neurological immune-related adverse events (irAEs) due to ICIs are rare; only $0.93 \%$ of patients with ICI treatment experience neurological side effects, such as neuropathy, noninfective meningitis, encephalitis, and neuromuscular disorders (3).

Among neuronal autoantibodies related to PNS, anti-Hu antibody recognizes the nucleus of all central nervous system neurons and causes limbic encephalitis (LE), subacute cerebellar degeneration, and polyneuropathy. PNS with anti$\mathrm{Hu}$ antibody was commonly seen in $78 \%$, of small-cell lung cancer (SCLC) patients; 73\% showed signs and symptoms of multifocal involvement of the nervous system, while $74 \%$ had sensory neuronopathy (2). In addition to anti-Hu antibody, anti-SOX-1 antibody recognizes the nuclear protein of glial cells and causes axonal neuropathy, demyelinating neuropathy, sensory and motor disorders (4). Five of 55 (9.1\%) anti-SOX-1 antibody-positive patients reportedly had coexisting anti-Hu antibodies in SCLC patients (5).

Sensory polyneuropathy has clinically been recognized due to the advent of ICIs (3); however, neurological adverse

${ }^{1}$ Department of Respiratory Medicine, Kitakyushu General Hospital, Japan and ${ }^{2}$ Department of Respiratory Medicine, University of Occupational and Environmental Health, Japan

Received: June 17, 2020; Accepted: November 1, 2020; Advance Publication by J-STAGE: December 15, 2020

Correspondence to Dr. Kei Yamasaki, yamasaki@med.uoeh-u.ac.jp 
Table 1. Laboratory Data on Admission.

\begin{tabular}{|c|c|c|c|c|c|}
\hline \multicolumn{2}{|c|}{$<$ Blood cell counts $>$} & \multirow{2}{*}{$\begin{array}{l}\text { T-bil } \\
\text { AST }\end{array}$} & \multirow{2}{*}{$\begin{array}{l}0.8 \mathrm{mg} / \mathrm{dL} \\
28 \mathrm{IU} / \mathrm{L}\end{array}$} & \multirow{2}{*}{$\begin{array}{l}\text { ANA } \\
\text { Anti-SS-A }\end{array}$} & \multirow{2}{*}{$\begin{array}{l}(-) \\
(-)\end{array}$} \\
\hline WBC & $5,100 / \mu \mathrm{L}$ & & & & \\
\hline Neutrophils & $72.2 \%$ & ALT & $37 \mathrm{IU} / \mathrm{L}$ & Anti-SS-B & $(-)$ \\
\hline Lymphocytes & $21.1 \%$ & $\mathrm{LDH}$ & $224 \mathrm{IU} / \mathrm{L}$ & vit.B1 & $41.9 \mathrm{ng} / \mathrm{mL}$ \\
\hline Eosinophils & $0.6 \%$ & $\gamma$-GTP & $49 \mathrm{IU} / \mathrm{L}$ & vit.B12 & $539 \mathrm{pg} / \mathrm{mL}$ \\
\hline Monocytes & $5.5 \%$ & BUN & $11.3 \mathrm{mg} / \mathrm{dL}$ & CEA & $2.5 \mathrm{ng} / \mathrm{mL}$ \\
\hline Basophils & $0.6 \%$ & Cre & $0.88 \mathrm{mg} / \mathrm{dL}$ & CYFRA21-1 & $1.7 \mathrm{ng} / \mathrm{mL}$ \\
\hline $\mathrm{RBC}$ & $5.36 \times 10^{6} / \mu \mathrm{L}$ & $\mathrm{Na}$ & $141 \mathrm{mEq} / \mathrm{L}$ & Pro-GRP & $541.5 \mathrm{pg} / \mathrm{mL}$ \\
\hline $\mathrm{Hb}$ & $17.1 \mathrm{~g} / \mathrm{dL}$ & $\mathrm{K}$ & $4.1 \mathrm{mEq} / \mathrm{L}$ & \multicolumn{2}{|c|}{$<$ Cerebrospinal fluid $>$} \\
\hline $\mathrm{Ht}$ & $49.1 \%$ & $\mathrm{Cl}$ & $107 \mathrm{mEq} / \mathrm{L}$ & Cell & $1 / \mu \mathrm{L}$ \\
\hline Platelets & $18.3 \times 10^{4} / \mu \mathrm{L}$ & Glucose & $156 \mathrm{mg} / \mathrm{dL}$ & Mono & $1 / \mu \mathrm{L}$ \\
\hline \multicolumn{2}{|c|}{$<$ Blood chemistry $>$} & HbA1c & $6.3 \%$ & Protein & $146 \mathrm{mg} / \mathrm{dL}$ \\
\hline TP & $7.9 \mathrm{~g} / \mathrm{dL}$ & CRP & $0.02 \mathrm{mg} / \mathrm{dL}$ & Glucose & $57 \mathrm{mg} / \mathrm{dL}$ \\
\hline $\mathrm{Alb}$ & $4.6 \mathrm{~g} / \mathrm{dL}$ & $\mathrm{RF}$ & $<0.1 \mathrm{IU} / \mathrm{mL}$ & Cytology & No malignancy \\
\hline
\end{tabular}

WBC: white blood cell, RBC: red blood cell, Hb: hemoglobin, Ht: hematocrit, TP: total protein, Alb: albumin, T-bil: total bilirubin, AST: aspartate aminotransferase, ALT: alanine aminotransferase, LDH: lactate dehydrogenase, ALP: alkaline phosphatase, $\gamma$-GTP: gamma-glutamyl transferase, BUN: blood urea nitrogen, Cre: creatinine, CRP: c-reactive protein, RF: rheumatoid factor, ANA: anti nuclear antibody, Anti-SS-A: anti Sjögren syndrome-A antibody, Anti-SS-B: anti Sjögren syndrome-B antibody, vit.B1: vitamin B1, vit.B12: vitamin B12, CEA: carcinoembryonic antigen, CYFRA: cytokeratin fragment, Pro-GRP: pro-gastrin-releasing peptide

events (nAEs) of ICIs, such as sensory polyneuropathy, are considered PNS and are still rare in patients with lung cancer. We herein report the first SCLC patient with sensory polyneuropathy who tested positive for anti-neuronal antibodies after initial treatment with anti programmed deathligand 1 (PD-L1) antibody combined with cytotoxic agents.

\section{Case Report}

A 70-year-old current-smoking (80 pack-years) Japanese man with a history of hypertension and nonrecurrent colon cancer was admitted to our hospital. Two months earlier, he had experienced dizziness and been diagnosed with brain stem hemorrhaging due to cavernous malformation (hemangioma). In addition, multiple nodules suspected of being brain metastases had been seen on enhanced magnetic resonance imaging (MRI). He has been treated with concentrated glycerin and fructose at a previous hospital, and his symptoms had completely disappeared.

Upon admission to our hospital, a physical examination revealed the following: height, $171.5 \mathrm{~cm}$; body weight, 74.1 $\mathrm{kg}$; body temperature, $35.9^{\circ} \mathrm{C}$; heart rate, $103 \mathrm{bpm}$; blood pressure, 107/71 $\mathrm{mmHg}$; and oxygen saturation, 95\% (room air, at rest); no neurological abnormalities were observed. Laboratory results (Table 1) showed a high titer of progastrin-releasing peptide (pro-GRP; $541.5 \mathrm{pg} / \mathrm{mL}$ ) and a low titer of carcinoembryonic antigen (CEA; $2.5 \mathrm{ng} / \mathrm{mL})$ and cytokeratin fragment 21-1 (CYFRA21-1; $1.7 \mathrm{ng} / \mathrm{mL}$ ). Chest radiography and high-resolution computed tomography showed two nodules in the right lower lobe with hilar lymphadenopathies. Sputum samples for a cytological examination were not available. Invasive pathological examinations, including bronchoscopy, could not be carried out because the patient was at a high risk of recurrent intracranial hemorrhaging due to cavernous hemangioma. The serum proGRP titer has a sensitivity of $86.4 \%$, specificity of $96.4 \%$, positive predictive value of $96.7 \%$, and negative predictive value of $84.4 \%$ for discriminating SCLC from non-SCLC (cut-off $77.8 \mathrm{pg} / \mathrm{mL}$ ) (6), and a titer of over $329.3 \mathrm{pg} / \mathrm{mL}$ pro-GRP also suggests extensive SCLC rather than limited disease (6). The high serum level of pro-GRP (541.5 pg/mL) in this patient was thus considered a marker of SCLC. Consequently, he was clinically diagnosed with stage IV SCLC based on the radiological and serological findings.

As the first-line treatment, combination therapy with carboplatin [area under the concentration-time curve (AUC) 5], etoposide $\left(100 \mathrm{mg} / \mathrm{m}^{2}\right)$, and atezolizumab $(1,200 \mathrm{mg}$ ) was administered (Figure). Three weeks after the chemotherapy, whole-brain irradiation $(3 \times 10$ Gy) was performed. Four weeks after chemotherapy, tactile and pain disturbances consistent with L2-3 dermatome, loss of bilateral patellar tendon reflexes, and loss of bilateral Achilles tendon reflexes were revealed. No obvious weakness was observed in the manual muscle strength test, Babinski reflexes were negative, and lower limb Barre's sign was positive. Coordination was poor in the finger-nose-finger test and knee-heel test, and gait was oscillating. Lumbar puncture results (Table 1) showed protein cell dissociation and no malignant cells. Enhanced brain MRI showed no evidence of recurrent brain stem hemorrhaging, and the size of all metastatic brain tumors had decreased. Lumbar spinal contrast-enhanced MRI showed no abnormal contrast enhancement of peripheral nerves, and nerve root compression consistent with the symptoms was observed. Serum anti-Hu and anti-SOX-1 antibody tests were both positive, and tests for onconeural antibodies (including anti-CV2, anti-Yo, anti-Ri, anti- 


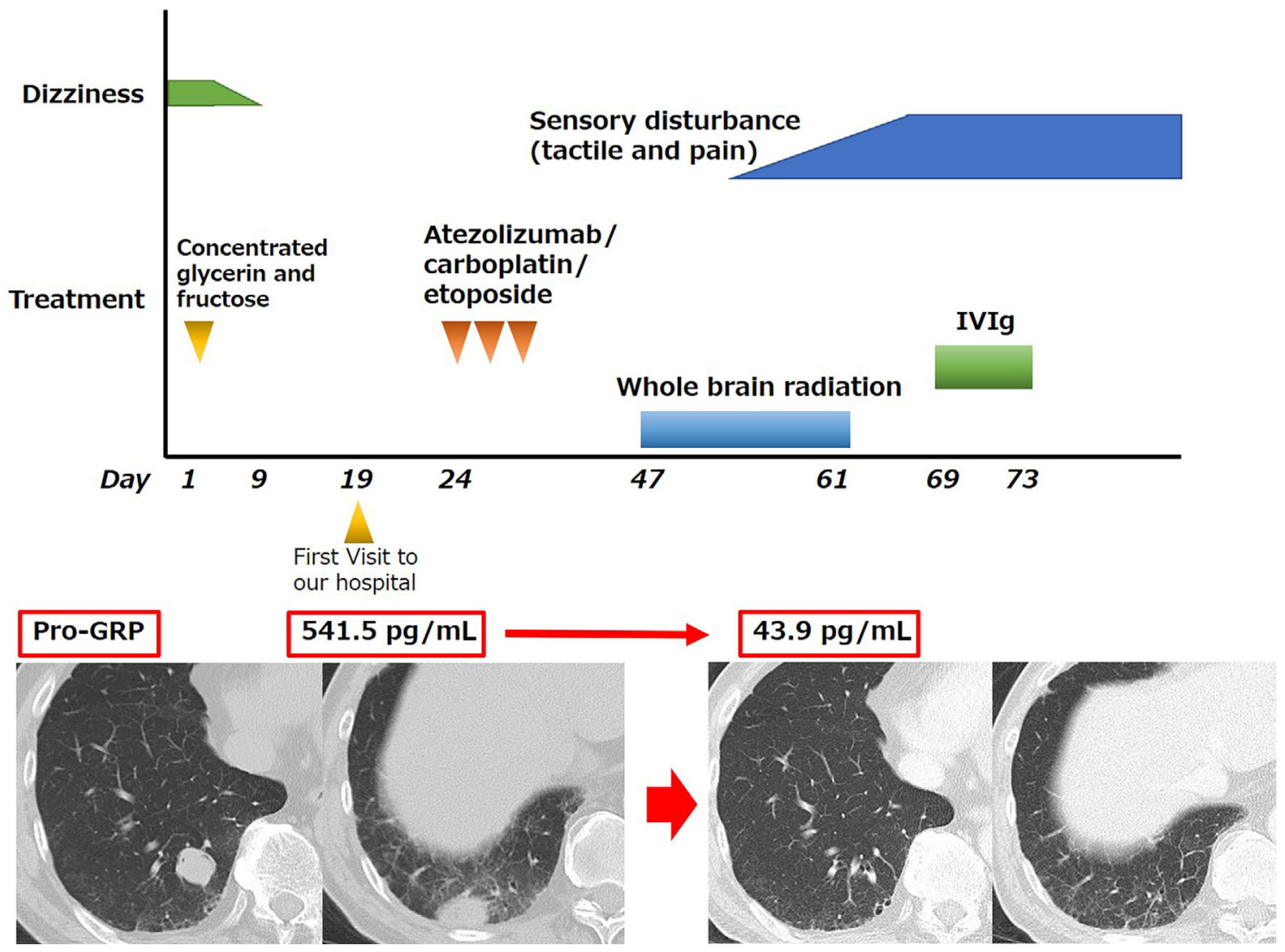

Figure. Clinical course of the patient. IVIg: intravenous immunoglobulin therapy, Pro-GRP: progastrin-releasing peptide

Table 2. The Nerve Conduction Study.

\begin{tabular}{lccccc}
\hline \multicolumn{1}{c}{ MCS } & $\begin{array}{c}\text { Distal latency } \\
(\mathrm{msec})\end{array}$ & $\begin{array}{c}\text { CMAP amplitude } \\
(\mathrm{mV})\end{array}$ & $\begin{array}{c}\text { MCV } \\
(\mathrm{m} / \mathrm{s})\end{array}$ & $\begin{array}{c}\text { SNAP } \\
(\mu \mathrm{V})\end{array}$ & $\begin{array}{c}\text { SCV } \\
(\mathrm{m} / \mathrm{s})\end{array}$ \\
\hline Rt. Median & 3.4 & 18.9 & 50.9 & 18.1 & 50.9 \\
Rt. Ulnar & 3 & 15.4 & 46.8 & 12.5 & 47 \\
Rt. Peroneal & 5.4 & 13.8 & 42 & - & - \\
Rt. Tibial & 6.1 & 18.1 & 38.3 & - & - \\
Rt. Sural & 3.8 & - & - & not evoked & not evoked \\
\hline
\end{tabular}

MCS: motor conduction study, SCS: sensory conduction study, CAMP: compound muscle action potential, SNAP: sensory nerve action potential, MCV: motor conduction velocity, SCV: sensory conduction velocity, Rt: right

amphiphysin, anti-paraneoplastic antigen MA2, antirecoverin, anti-titin, anti-ZIC4, anti-GAD65 and anti-Tr) were all negative. Nerve conduction testing revealed that amplitude of sensory nerves was not evoked, and no apparent abnormalities in motor nerves were observed (Table 2).

Based on the neurological findings and results of the nerve conduction test, the patient was diagnosed with sensory polyneuropathy. After systemic chemotherapy with atezolizumab and radiotherapy to the brain, the chest and brain tumors had shrunk, and the elevated serum level of pro-GRP had drastically decreased from 541.5 to $43.9 \mathrm{pg} / \mathrm{mL}$. The clinical timeline of the onset of neurological symptoms was indicative of chemotherapy, particularly atezolizumabinduced. Intravenous immunoglobulin (IVIg) therapy was administered after the first round of systemic chemotherapy, but his neurological symptoms did not improve.

\section{Discussion}

Our patient with suspected SCLC who experienced an nAE of sensory polyneuropathy tested positive for antineuronal antibodies after initial treatment with atezolizumab in combination with carboplatin and etoposide.

Anti-acetylcholine receptor antibodies are generally pathogenic (e.g., in myasthenia gravis), but not all lung cancer patients positive for anti-Hu antibodies show neurological symptoms; indeed, among 196 SCLC patients with anti-Hu antibodies, 31 patients (16\%) had no neurological symptoms (7). In relation to the treatment with ICIs and PNS with anti-Hu antibody, nivolumab (anti-PD-1 antibody)- 
induced sensory neuropathy (8), nivolumab-induced LE (9), sintilimab-induced LE, and enteric neuropathy (10) have been reported.

Regarding the etiology of PNS, the decreased expression of multiple Treg-related genes involved in immune regulation in SCLC patients might cause impaired immune tolerance, tissue damage due to autoimmune mechanisms, and PNS (11). PD-L1-coated beads can induce Tregs in vitro, and PD-L1 increases Foxp3 expression and enhances the immunosuppressive ability of Tregs (12), suggesting that antiPD-L1 antibody treatment may suppress Treg infiltration into tumors. Hence, the present patient was positive for antineuronal antibodies, but the neurological symptoms manifested after chemotherapy, suggesting that the PNS was evoked by an ICI, such as atezolizumab, and cytotoxic agents.

In the management of PNS, underlying disease treatments, such as anticancer therapy, are prioritized, which may partly improve neurological symptoms; however, only $10-20 \%$ of patients achieve improvement in their neurological symptoms (13). For patients in whom neurological symptoms persist, plasma exchange, systemic corticosteroids, immunosuppressants, or IVIg therapy are considered but usually prove to be ineffective (14). Thus far, there have been no available data concerning randomized controlled trials for the treatment of PNS; the available data have only been collected from case series, case reports, or expert opinions (class IV evidence) regarding the effect of immunomodulation (IVIg, steroid treatment, plasma exchange, or chemotherapy) on paraneoplastic neuropathy (15). In our case study, although the patient was treated with a high-dose immunoglobulin, no neurological improvement was noted. In addition, the relationship between the presence of antineurological antibodies and the prognosis of neurological symptoms remains controversial $(16,17)$.

Several limitations associated with the present study warrant mention. First, even though anticancer treatment was performed, there was no pathological evidence of lung cancer. There might have been other differential diagnoses, such as non-SCLC, carcinoid, large-cell neuroendocrine carcinoma, and infectious diseases. Second, as this patient had already presented with neurological symptoms at a previous hospital due to hemorrhaging of cavernous malformation, the discrimination of neurological symptoms of irAEs should have been carefully deliberated. However, the intracranial hemorrhagic symptoms had completely disappeared following treatment with concentrated glycerin and fructose before systemic chemotherapy, and sensory disturbances due to irAEs appeared four weeks after chemotherapy; the disturbances were consistent with those of PNS (Figure). Therefore, we believe that the etiology of the two neurological symptoms are clearly distinguishable. Third, the patient was treated with atezolizumab in combination with carboplatin and etoposide; therefore, the specific agent causing PNS was clinically unclear. However, both ICIs and cytotoxic agents have been reported to cause PNS, suggesting that combination therapy with ICIs and cytotoxic agents may increase the incidence of PNS.

\section{Conclusion}

In conclusion, we herein report an anti-Hu and anti-SOX1 antibody dual-positive patient with suspected SCLC induced by combination treatment with carboplatin, etoposide, and atezolizumab. This irAE is often intractable, so physicians should be aware of this side effect, especially when treating patients with anti-neuronal antibodies using the combination of an ICI and cytotoxic agents.

\section{The authors state that they have no Conflict of Interest (COI).}

\section{References}

1. Honnorat J, Antoine JC. Paraneoplastic neurological syndromes. Orphanet J Rare Dis 2: 22, 2007.

2. Dalmau J, Graus F, Rosenblum MK, Posner JB. Anti-Huassociated paraneoplastic encephalomyelitis/sensory neuronopathy. A clinical study of 71 patients. Medicine (Baltimore) 71: 59-72, 1992.

3. Larkin J, Chmielowski B, Lao CD, et al. Neurologic serious adverse events associated with nivolumab plus ipilimumab or nivolumab alone in advanced melanoma, including a case series of encephalitis. Oncologist 22: 709-718, 2017.

4. Tschernatsch M, Singh P, Gross O, et al. Anti-SOX1 antibodies in patients with paraneoplastic and non-paraneoplastic neuropathy. J Neuroimmunol 226: 177-180, 2010.

5. Stich O, Klages E, Bischler $P$, et al. SOX1 antibodies in sera from patients with paraneoplastic neurological syndromes. Acta Neurol Scand 125: 326-331, 2012.

6. Cavalieri S, Morelli D, Martinetti A, et al. Clinical implications for pro-GRP in small cell lung cancer. A single center experience. Int J Biol Markers 33: 55-61, 2018.

7. Graus F, Dalmou J, Rene R, et al. Anti-Hu antibodies in patients with small-cell lung cancer: association with complete response to therapy and improved survival. J Clin Oncol 15: 2866-2872, 1997.

8. Raibagkar P, Ho D, Gunturu KS, Srinivasan J. Worsening of anti$\mathrm{Hu}$ paraneoplastic neurological syndrome related to anti-PD-1 treatment: case report and review of literature. J Neuroimmunol 341: 577184, 2020.

9. Matsuoka H, Kimura H, Koba H, et al. Nivolumab-induced limbic encephalitis with anti-Hu antibody in a patient with advanced pleomorphic carcinoma of the lung. Clin Lung Cancer 19: e597-e 599, 2018.

10. Kang K, Zheng K, Zhang Y. Paraneoplastic encephalitis and enteric neuropathy associated with anti-Hu antibody in a patient following immune-checkpoint inhibitor therapy. J Immunother 43: 165-168, 2020.

11. Tani T, Tanaka K, Idezuka J, Nishizawa M. Regulatory $T$ cells in paraneoplastic neurological syndromes. J Neuroimmunol 196: 166169, 2008.

12. Francisco LM, Salinas VH, Brown KE, et al. PD-L1 regulates the development, maintenance, and function of induced regulatory $\mathrm{T}$ cells. J Exp Med 206: 3015-3029, 2009.

13. Grisold W, Drlicek M, Liszka-Setinek U, Wondrusch E. Antitumour therapy in paraneoplastic neurological disease. Clin Neurol Neurosurg 97: 106-111, 1995.

14. Graus F, Vega F, Delattre JY, et al. Plasmapheresis and antineoplastic treatment in CNS paraneoplastic syndromes with antineuronal autoantibodies. Neurology 42: 536-540, 1992.

15. Giometto B, Vitaliani R, Lindeck-Pozza E, Grisold W, Vedeler C. 
Treatment for paraneoplastic neuropathies. Cochrane Database Syst Rev 12: Cd007625, 2012.

16. Vedeler CA, Antoine JC, Giometto B, et al. Management of paraneoplastic neurological syndromes: report of an EFNS Task Force. Eur J Neurol 13: 682-690, 2006.

17. Candler PM, Hart PE, Barnett M, Weil R, Rees JH. A follow up study of patients with paraneoplastic neurological disease in the
United Kingdom. J Neurol Neurosurg Psychiatry 75: 1411-1415, 2004.

The Internal Medicine is an Open Access journal distributed under the Creative Commons Attribution-NonCommercial-NoDerivatives 4.0 International License. To view the details of this license, please visit (https://creativecommons.org/licenses/ by-nc-nd/4.0/).

(C) 2021 The Japanese Society of Internal Medicine Intern Med 60: 1577-1581, 2021 